\title{
New Synthetic Pyridine Derivate as Potential Elicitor in Production of Isoflavonoids and Flavonoids in Trifolium pratense L. Suspension Culture
}

\author{
Marie Kašparová, ${ }^{1}$ Tomáš Siatka, ${ }^{1}$ Věra Klimešová, ${ }^{2}$ and Jaroslav Dušek1 \\ ${ }^{1}$ Department of Pharmacognosy, Faculty of Pharmacy in Hradec Králové, Charles University in Prague, \\ Heyrovského 1203, 50005 Hradec Králové, Czech Republic \\ ${ }^{2}$ Department of Inorganic and Organic Chemistry, Faculty of Pharmacy in Hradec Králové, Charles University in Prague, \\ Heyrovského 1203, 50005 Hradec Králové, Czech Republic
}

Correspondence should be addressed to Marie Kašparová, kasparova@faf.cuni.cz

Received 21 October 2011; Accepted 14 December 2011

Academic Editor: Luigi M. Chiechi

Copyright (C) 2012 Marie Kašparová et al. This is an open access article distributed under the Creative Commons Attribution License, which permits unrestricted use, distribution, and reproduction in any medium, provided the original work is properly cited.

The production of secondary metabolites in Trifolium pratense L. suspension culture of the family of legume plants (Fabaceae) is low, and therefore there was an attempt to increase it by elicitation. New synthetic substance, 2-(2-fluoro-6-nitrobenzylsulfanyl)pyridine-4-carbothioamide, was tested as elicitor-a substance that showed the best elicitation effect after 48-hour application of $1 \mu \mathrm{mol} \mathrm{L}{ }^{-1}$ concentration. Maximum contents of genistin $\left(11.60 \mathrm{mg} \mathrm{g}^{-1} \mathrm{DW}\right)$, daidzein $\left(8.31 \mathrm{mg} \mathrm{g}^{-1} \mathrm{DW}\right)$, and genistein $\left(1.50 \mathrm{mg} \mathrm{g}^{-1} \mathrm{DW}\right)$ were recorded, and the production of these isoflavonoids thus significantly increased, when compared with the control, by $152 \%, 151 \%$, and $400 \%$. The maximum content of flavonoids $\left(5.78 \mathrm{mg} \mathrm{g}^{-1} \mathrm{DW}\right)$ and the increase in the production by $142 \%$, when compared with the control, were induced by 6 -hour application of $100 \mu \mathrm{mol} \mathrm{L}{ }^{-1}$ concentration. The tested substance showed to be an effective elicitor of phenylpropane metabolism.

\section{Introduction}

Isoflavonoids and flavonoids are, due to their wide spectrum of biological effects, some of the closely studied secondary metabolites of plants $[1,2]$. Their major producers are plants of the legume family (Fabaceae). Trifolium pratense (red clover) contains especially the following isoflavonoids: daidzein, formononetin, biochanin $\mathrm{A}$, and genistein. The contents of isoflavones were determined in the root, stem, leaf, and bloom of red clover. The highest and nearly equal concentrations were found in the root, stem, and leaf, least of all in bloom [3]. A total of 28 phenolic compounds were identified by high-performance liquid chromatography and mass spectrometry in red clover roots. The most abundant isoflavonoids in pot-grown roots were formononetin glycoside malonate (G-M) (1.51-4.26 $\left.\mathrm{mg} \mathrm{g}^{-1} \mathrm{DW}\right)$, formononetin (2.21-3.57 $\left.\mathrm{mg} \mathrm{g}^{-1} \mathrm{DW}\right)$, and biochanin A (1.73-2.17 $\mathrm{mg} \mathrm{g}^{-1}$ $\mathrm{DW}$ ), whereas field-grown roots were rich in formononetinG-M (3.90-4.27 $\left.\mathrm{mg} \mathrm{g}^{-1} \mathrm{DW}\right)$ and pseudobaptigenin-G-M (1.80-2.58 $\left.\mathrm{mg} \mathrm{g}^{-1} \mathrm{DW}\right)$. Elevated ozone, cultivation regime, and growth stage affected the levels of phenolics in red clover roots, suggesting sensitivity of root phenolics to biotic and abiotic stress conditions [1].

These isoflavonoids are considered the most important phytoestrogens because of their ability to interact with estrogenic receptors and because of their structural similarity with $17 \beta$-estradiol $[4,5]$. The red clover extracts are used in female menopause nonhormonal substitution therapy. They decrease the occurrence of menopausal syndromes; have positive effect in the prevention of osteoporosis; reduce the risk of the incidence of cardiovascular diseases and the breast cancer [6-8]. A positive impact of these isoflavonoids in the prostate gland cancer prevention was also noted [9].

In vitro methods provide opportunities for propagating and preserving endangered plant species when seed-based methods are not adequate. Tissue culture propagation methods can be used to produce such plants for reintroduction, research, education, display, and commerce. They can also be the basis for tissue banking as a way to preserve genetic 
diversity when seeds cannot be banked. The number of endangered species that will require in vitro methods is estimated to be at least 5,000 worldwide [10]. The plant tissue cultures are a promising source of secondary metabolites. However, their production, when compared with intact plants, is usually lower, and this is the reason why we are looking for different methods and approaches to increase the production. Many traditional strategies can be used to increase the production of secondary metabolites but elicitation is usually one of the most successful.

The principle of elicitation consists in the accumulation of the secondary substances in the plants - a process that is a part of the plant's defense reaction against the influences caused by pathogens or by the plant's environment. The factors that trigger the defensive reactions are called elicitors. Elicitation strengthens the transcription of genes, for instance, phenylpropane metabolism, thus genes that code enzymes which are necessary for synthesis of isoflavonoids and flavonoids (phenylalanine ammonia lyase, chalcone synthase, etc.) [11-13]. The most commonly used elicitors are, for example, fungal homogenates, heavy metals, physical factors, and phytohormones [14-18].

The elicitation method was also used during experiments to influence the Trifolium pratense suspension culture production. The best elicitation effects so far have been detected at mercury chloride and at jasmonic acid $[18,19]$.

Recently, newly synthesized chemical substances have been tested as elicitors in in vitro plant cultures. Many of them have proven to possess strong elicitation effect. For instance, fluoro derivates of jasmonic acid [20] and chlorinated pyridine derivates can also be considered suitable chemical induction signals of secondary metabolism of plants [21]. In cases of the Ononis arvensis, Silybum marianum, and Genista tinctoria tissue cultures, synthetic derivates pyrazine-2-carboxamides were observed to be potential elicitors. A more suitable elicitor for the production of isoflavonoids in the callus culture of Genista tinctoria proved to be substance B (5-terc-butyl-6-chloro-N-(3-iodo-4-methylphenyl)pyrazine-2-carboxamide). The absolute maximum of genistin production was achieved by a 12-hour action of substance $B$ in a concentration of $2.3310^{-3} \mathrm{~mol} \mathrm{~L}^{-1}$ (57 times versus control) [22]. Substituted pyrazinecarboxamides markedly influenced production of flavonolignans in Silybum marianum callus and suspension cultures. The highest increase in production of flavonoids, by $900 \%$, was detected in the Ononis arvensis callus culture [23].

A newly synthesized benzylsulfanylpyridine derivate, 2-(2-fluoro-6-nitrobenzylsulfanyl)pyridine-4-carbothioamide), originally prepared as antimycobacterial or antifungal compound, also influences the plant metabolism - it inhibits photosynthesis in spinach chloroplasts [24]. Therefore, the aim of this study was to prove this compound as a potential elicitor of biosynthesis of isoflavonoids and flavonoids in the Trifolium pratense suspension culture.

\section{Materials and Methods}

2.1. Instruments. A $200 \mathrm{~S}$ analytical scales made by Sartorius, Göttingen; a PS 20A autoclave by Chirana, Brno; as HS 31A hot-air sterilizer by Chirana, Brno; a laminar flow workbench by Fatran LF, Žilina; a roller by Vývojove Dílny AV ČR, Praha; a 2010 shaker by Unimax, Heidolph; a CE 1010 spectrophotometer by Cecil instruments, Cambridge; a liquid chromatography (PU-2089 pump, MD-2015 detector, AS2055 automatic sample injector) by JASCO, Tokyo.

2.2. Trifolium pretense L. Suspension Culture. A callus culture was derived from the seedling of red clover (tetraploid variety DO- 8 obtained from the Breeding Station Domoradice, Czech Republic). The suspension culture was then derived from 1-year old callus culture mechanically by shaking in the Gamborg liquid nutrient medium [25] supplemented with $2 \mathrm{mg} \mathrm{L}^{-1}$ of 2,4-dichlorophenoxyacetic acid and $2 \mathrm{mg} \mathrm{L}^{-1}$ of 6-benzylaminopurine. The culture was cultivated on a roller at the temperature of $25^{\circ} \mathrm{C}$, and a $16 \mathrm{hr}$ light $/ 8 \mathrm{hr}$ dark photoperiod. The subcultivation interval lasted 14 days. Growth and production characteristics of this culture were determined; an obvious indirect relationship between growth rate and accumulation of secondary metabolites was observed [26].

2.3. Elicitation. For elicitation experiments, we used 6month old suspension culture and the elicitor in the concentrations of $1 \mu \mathrm{mol} \mathrm{L}-1,10 \mu \mathrm{mol} \mathrm{L}^{-1}$, and $100 \mu \mathrm{mol} \mathrm{L}^{-1}$ dissolved in $96 \%$ ethanol. $1 \mathrm{~mL}$ of the elicitor solution was added to each flask (containing $25 \mathrm{~mL}$ of the suspension culture) before the end of the exponential growth phase of the culture (on the 21st day of cultivation) [26]. The durations of the elicitor applications were $6,24,48$, and 168 hours, then the elicited cultures were gathered. $1 \mathrm{~mL}$ of $96 \%$ ethanol was added to the control cultures. Inspection cultures were collected after 6 and 168 hours since their production does not change notably in such short time intervals. The cells were separated from the media by vacuum filtration, rinsed with distilled water, and dried at the laboratory temperature. The nutrient medium was kept frozen to be used for subsequent analyses. All analyses were carried out in a minimum of three independent samples for each elicitation period and each concentration of elicitor.

2.4. Determining the Flavonoids and Isoflavonoids. Spectrophotometric determination of flavonoids was carried out in the extracts of the cells and in the culture media according to the Czech Pharmacopoeia 2009 [27]. The HPLC method with fluorometric detection was used to determine isoflavonoids [28]. A $200 \mathrm{mg}$ sample was extracted twice (in a water bath under reflux condenser) with $10 \mathrm{~mL}$ of $80 \%(\mathrm{v} / \mathrm{v})$ aqueoes methanol for $20 \mathrm{~min}$. The filtrated extracts were combined, and the volume was adjusted with $80 \%$ (v/v) aqueoes methanol to $25 \mathrm{~mL}$. After filtration through a $0.45 \mu \mathrm{m}$ microfilter, the extracts were injected into the HPLC system. Also samples of the culture media were filtrated through a $0.45 \mu \mathrm{m}$ microfilter and injected into the HPLC system. The HPLC conditions were as follows: a RP-18 Lichrospher column $(250 \times 4 \mathrm{~mm}$, particles size $5 \mu \mathrm{m})$ with a precolumn made of the same material; elution: linear gradient of a mobile phase A (methanol) in phase B (water containing $0.15 \%(\mathrm{v} / \mathrm{v})$ of phosphoric acid) $30-80 \%(\mathrm{v} / \mathrm{v})$ from 0 to 9 
TABLe 1: Production of isoflavonoids in the suspension culture of Trifolium pratense.

\begin{tabular}{|c|c|c|c|c|c|c|}
\hline $\begin{array}{l}\text { Elicitor concentration } \\
\left(\mu \mathrm{mol} \mathrm{L}^{-1}\right)\end{array}$ & $\begin{array}{c}\text { Time after } \\
\text { elicitation (hours) }\end{array}$ & $\begin{array}{c}\text { Genistin } \\
\left(\mathrm{mgg}^{-1} \mathrm{DW}\right)\end{array}$ & $\begin{array}{c}\text { Daidzein } \\
\left(\mathrm{mgg}^{-1} \mathrm{DW}\right)\end{array}$ & $\begin{array}{c}\text { Genistein } \\
\left(\mathrm{mgg}^{-1} \mathrm{DW}\right)\end{array}$ & $\begin{array}{c}\text { Formononetin } \\
\left(\mathrm{mgg} \mathrm{g}^{-1} \mathrm{DW}\right)\end{array}$ & $\begin{array}{l}\text { Biochanin A } \\
\left(\mathrm{mgg}^{-1} \mathrm{DW}\right)\end{array}$ \\
\hline \multirow{4}{*}{0 (control) } & 6 & $4.61 \pm 0.03$ & $3.32 \pm 0.08$ & $0.31 \pm 0.05$ & $3.69 \pm 0.09$ & $0.28 \pm 0.04$ \\
\hline & 24 & $4.61 \pm 0.03$ & $3.32 \pm 0.08$ & $0.31 \pm 0.05$ & $3.69 \pm 0.09$ & $0.28 \pm 0.04$ \\
\hline & 48 & $4.61 \pm 0.03$ & $3.32 \pm 0.08$ & $0.31 \pm 0.05$ & $3.69 \pm 0.09$ & $0.28 \pm 0.04$ \\
\hline & 168 & $6.30 \pm 0.05$ & $3.41 \pm 0.06$ & $1.19 \pm 0.02$ & $3.91 \pm 0.06$ & $0.31 \pm 0.02$ \\
\hline \multirow{4}{*}{1} & 6 & $7.21^{*} \pm 0.09$ & $2.61^{*} \pm 0.10$ & $0.52 \pm 0.10$ & $4.78^{*} \pm 0.10$ & $0.29 \pm 0.08$ \\
\hline & 24 & $8.89^{*} \pm 0.04$ & $5.99^{*} \pm 0.09$ & $0.88^{*} \pm 0.05$ & $1.12^{*} \pm 0.08$ & $0.12 \pm 0.12$ \\
\hline & 48 & $11.60^{*} \pm 0.07$ & $8.31^{*} \pm 0.04$ & $1.50^{*} \pm 0.06$ & $5.83^{*} \pm 0.05$ & $0.21 \pm 0.07$ \\
\hline & 168 & $1.31^{*} \pm 0.12$ & $0.32^{*} \pm 0.07$ & $0.23^{*} \pm 0.04$ & $0.71^{*} \pm 0.04$ & $0.09^{*} \pm 0.03$ \\
\hline \multirow{4}{*}{10} & 6 & $11.49^{*} \pm 0.08$ & $2.98^{*} \pm 0.04$ & $1.32^{*} \pm 0.08$ & $7.31^{*} \pm 0.05$ & $0.28 \pm 0.09$ \\
\hline & 24 & $7.71^{*} \pm 0.10$ & $3.13 \pm 0.09$ & $0.31 \pm 0.02$ & $6.53^{*} \pm 0.09$ & $0.00^{*} \pm 0.00$ \\
\hline & 48 & $7.39^{*} \pm 0.05$ & $2.49^{*} \pm 0.06$ & $0.48 \pm 0.13$ & $3.62 \pm 0.11$ & $0.11^{*} \pm 0.02$ \\
\hline & 168 & $2.20^{*} \pm 0.07$ & $0.62^{*} \pm 0.10$ & $0.19^{*} \pm 0.05$ & $0.42 * \pm 0.05$ & $0.11^{*} \pm 0.05$ \\
\hline \multirow{4}{*}{100} & 6 & $5.11^{*} \pm 0.04$ & $2.67^{*} \pm 0.15$ & $0.42 \pm 0.06$ & $0.59^{*} \pm 0.07$ & $0.29 \pm 0.07$ \\
\hline & 24 & $7.19^{*} \pm 0.09$ & $2.92^{*} \pm 0.08$ & $0.00^{*} \pm 0.00$ & $0.72^{*} \pm 0.04$ & $0.19 \pm 0.04$ \\
\hline & 48 & $8.78^{*} \pm 0.11$ & $2.42^{*} \pm 0.03$ & $0.14^{*} \pm 0.05$ & $2.90^{*} \pm 0.06$ & $0.11^{*} \pm 0.02$ \\
\hline & 168 & $0.67^{*} \pm 0.07$ & $0.23^{*} \pm 0.05$ & $0.32^{*} \pm 0.04$ & $1.89^{*} \pm 0.05$ & $0.08^{*} \pm 0.12$ \\
\hline
\end{tabular}

Levels marked with * are statistically significantly different compared with the control each value represents the mean of three samples \pm standard deviation.

minutes was followed by the isocratic elution with a mixture of $80 \%(\mathrm{v} / \mathrm{v})$ of phase $\mathrm{A}$ in phase B from 9 to 15 minutes; the flow rate was $1.1 \mathrm{~mL} \mathrm{~min}^{-1}$; the detection was carried out at the $260 \mathrm{~nm}$ wavelength. The contents of the monitored substances were quantified by using mathematical method of normalization and by comparing with the calibration curve drawn by the external standard of the same substance. The obtained results were statistically evaluated by the $t$-test at $P=0.05$.

\section{Results and Discussion}

Successful elicitation depends on many factors that are specific for each elicitor and for each plant tissue culture. This work focused on the elicitor concentration and time duration of elicitor's effect. The results (Table 1) indicate that the elicitor used influenced favorably the production of isoflavonoids in the Trifolium pratense suspension culture. The best elicitation effect was observed after 48-hour application of $1 \mu \mathrm{mol} \mathrm{L}{ }^{-1}$ concentration after which maximum amounts of genistin $\left(11.60 \mathrm{mg} \mathrm{g}^{-1} \mathrm{DW}\right)$, daidzein $\left(8.31 \mathrm{mg} \mathrm{g}^{-1} \mathrm{DW}\right)$, and genistein $\left(1.50 \mathrm{mg} \mathrm{g}^{-1} \mathrm{DW}\right)$ were determined. There was statistically significant increase in the production of the above-mentioned isoflavonoids, when compared with control, by $152 \%, 151 \%$, and $400 \%$, respectively. The positive effect of the elicitation grew with the duration time of the application $(6,24,48$ hours). On the contrary, maximum content of formononetin $\left(7.31 \mathrm{mg} \mathrm{g}^{-1} \mathrm{DW}\right)$ was determined after 6-hour application of $10 \mu \mathrm{mol} \mathrm{L}^{-1}$ concentration which represents a $97 \%$ increase when compared with control. The stimulation of genistin occurred even after adding the strongest, $100 \mu \mathrm{mol} \mathrm{L}^{-1}$ concentration. Only the production of biochanin A was not influenced favorably. Moreover, the longest (168-hour) application of all elicitor concentrations
TABLE 2: Production of flavonoids in the suspension culture of Trifolium pratense.

\begin{tabular}{lcc}
\hline $\begin{array}{l}\text { Elicitor concentration } \\
\left.(\mu \mathrm{mol} \mathrm{L})^{-1}\right)\end{array}$ & $\begin{array}{c}\text { Time after elicitation } \\
\text { (hours) }\end{array}$ & $\begin{array}{c}\text { Flavonoid contents } \\
\left(\mathrm{mg} \mathrm{g}^{-1} \mathrm{DW}\right)\end{array}$ \\
\hline \multirow{3}{*}{$($ control $)$} & 6 & $2.39 \pm 0.07$ \\
& 24 & $2.39 \pm 0.07$ \\
& 48 & $2.39 \pm 0.07$ \\
168 & $2.71 \pm 0.09$ \\
\hline & 6 & $4.87^{*} \pm 0.08$ \\
& 24 & $2.67^{*} \pm 0.06$ \\
& 48 & $2.69^{*} \pm 0.03$ \\
10 & 168 & $2.12^{*} \pm 0.04$ \\
\hline & 6 & $5.05^{*} \pm 0.12$ \\
& 24 & $2.72^{*} \pm 0.05$ \\
100 & 48 & $2.99^{*} \pm 0.02$ \\
& 168 & $2.11^{*} \pm 0.09$ \\
\hline & 6 & $5.78^{*} \pm 0.03$ \\
& 24 & $3.56^{*} \pm 0.05$ \\
\hline
\end{tabular}

Levels marked with * are statistically significantly different compared with the control. Each value represents the mean of three samples \pm standard deviation.

has decreased the production of isoflavonoids when compared with control.

The production of flavonoids in the elicited Trifolium pratense suspension culture (Table 2) was also successful. The best elicitation effect of all elicitor concentrations was recorded after 6 hours. The higher the elicitor concentration, the better the effect observed. The maximum content of 
flavonoids $\left(5.78 \mathrm{mg} \mathrm{g}^{-1} \mathrm{DW}\right)$ was induced by 6-hour application of the strongest, $100 \mu \mathrm{mol} \mathrm{L}^{-1}$ concentration of elicitor, and the increase of production was statistically significant-it increased by $142 \%$ when compared with the control. On the contrary, the positive influence of the elicitation was decreasing when the time duration of the elicitor application was prolonged. The longest, 168-hour application of all concentrations of elicitor caused (as in case of isoflavonoids) statistically significant decrease in the flavonoid content when compared with control.

The content of flavonoids and isoflavonoids was not only determined in the extracts of the cells but also in the nutrient media of Trifolium pratense suspension cultures. No detectable levels of these substances were found in any of the samples tested. There was thus no secretion of the monitored secondary metabolites into the nutrient medium after the application of this elicitor.

All obtained results indicate that the tested compound, 2-(2-fluoro-6-nitrobenzylsulfanyl)pyridine-4-carbothioamide, has shown to be an effective elicitor of phenylpropane metabolism.

\section{Acknowledgments}

This study was supported by the Ministry of Education of the Czech Republic (Project MSM 0021620822) and by the Charles University in Prague (Project SVV 263 004).

\section{References}

[1] N. M. M. Saviranta, R. Julkunen-Tiitto, E. Oksanen, and R. O. Karjalainena, "Red clover (Trifolium pratense L.) isoflavones: root phenolic compounds affected by biotic and abiotic stress factors," Journal of the Science of Food and Agriculture, vol. 90, no. 3, pp. 418-423, 2010.

[2] M. Łuczkiewicz and D. Głód, "Callus cultures of Genista plants - in Vitro material producing high amounts of isoflavones of phytoestrogenic activity," Plant Science, vol. 165, no. 5, pp. 1101-1108, 2003.

[3] Q. Wu, M. Wang, and J. E. Simon, "Determination of isoflavones in red clover and related species by high-performance liquid chromatography combined with ultraviolet and mass spectrometric detection," Journal of Chromatography A, vol. 1016, no. 2, pp. 195-209, 2003.

[4] A. M. Duncan, W. R. Phipps, and M. S. Kurzer, "Phyto-oestrogens," Best Practice and Research: Clinical Endocrinology and Metabolism, vol. 17, no. 2, pp. 253-271, 2003.

[5] T. Cornwell, W. Cohick, and I. Raskin, "Dietary phytoestrogens and health," Phytochemistry, vol. 65, no. 8, pp. 995-1016, 2004.

[6] M. Mueller, S. Hobiger, and A. Jungbauer, "Red clover extract: a source for substances that activate peroxisome proliferatoractivated receptor $\alpha$ and ameliorate the cytokine secretion profile of lipopolysaccharide-stimulated macrophages," Menopause, vol. 17, no. 2, pp. 379-387, 2010.

[7] L. A. Hidalgo, P. A. Chedraui, N. Morocho, S. Ross, and G. San Miguel, "The effect of red clover isoflavones on menopausal symptoms, lipids and vaginal cytology in menopausal women: a randomized, double-blind, placebo-controlled study," Gynecological Endocrinology, vol. 21, no. 5, pp. 257-264, 2005.
[8] V. Beck, U. Rohr, and A. Jungbauer, "Phytoestrogens derived from red clover: an alternative to estrogen replacement therapy?" Journal of Steroid Biochemistry and Molecular Biology, vol. 94, no. 5, pp. 499-518, 2005.

[9] P. L. De Souza, P. J. Russell, J. H. Kearsley, and L. G. Howes, "Clinical pharmacology of isoflavones and its relevance for potential prevention of prostate cancer," Nutrition Reviews, vol. 68, no. 9, pp. 542-555, 2010.

[10] V. C. Pence, "Evaluating costs for the in vitro propagation and preservation of endangered plants," In Vitro Cellular and Developmental Biology —Plant, vol. 47, no. 1, pp. 176-187, 2011.

[11] W. Jung, O. Yu, S. M. C. Lau et al., "Identification and expression of isoflavone synthase, the key enzyme for biosynthesis of isoflavones in legumes," Nature Biotechnology, vol. 18, no. 2, pp. 208-212, 2000.

[12] J. Zhao, L. C. Davis, and R. Verpoorte, "Elicitor signal transduction leading to production of plant secondary metabolites," Biotechnology Advances, vol. 23, no. 4, pp. 283-333, 2005.

[13] T. Nürnberger and D. Scheel, "Signal transmission in the plant immune response," Trends in Plant Science, vol. 6, no. 8, pp. 372-379, 2001.

[14] J. L. Zhao, L. G. Zhou, and J. Y. Wu, "Effects of biotic and abiotic elicitors on cell growth and tanshinone accumulation in Salvia miltiorrhiza cell cultures," Applied Microbiology and Biotechnology, vol. 87, no. 1, pp. 137-144, 2010.

[15] S. Goyal and K. G. Ramawat, "Increased isoflavonoids accumulation in cell suspension cultures of Pueraria tuberosa by elicitors," Indian Journal of Biotechnology, vol. 7, no. 3, pp. 378-382, 2008.

[16] T. Siatka and M. Kašparová, "Effects of aluminium chloride on cell growth and production of coumarins in cell suspension cultures of Angelica archangelica L.," Ceska a Slovenska Farmacie, vol. 59, no. 3, pp. 112-116, 2010.

[17] E. Kaimoyo, M. A. Farag, L. W. Sumner, C. Wasmann, J. L. Cuello, and H. VanEtten, "Sub-lethal levels of electric current elicit the biosynthesis of plant secondary metabolites," Biotechnology Progress, vol. 24, no. 2, pp. 377-384, 2008.

[18] M. Kašparová, T. Siatka, and J. Dušek, "Biotic elicitation of the Trifolium pratense L. suspension culture," Ceska a Slovenska Farmacie, vol. 57, no. 3, pp. 107-110, 2008.

[19] M. Kašparová, T. Siatka, and J. Dušek, "Production of isoflavonoids in the Trifolium pratense L. suspension culture," Ceska a Slovenska Farmacie, vol. 58, no. 2, pp. 67-70, 2009.

[20] Z. G. Qian, Z. J. Zhao, Y. Xu, X. Qian, and J. J. Zhong, "A novel synthetic fluoro-containing jasmonate derivative acts as a chemical inducing signal for plant secondary metabolism," Applied Microbiology and Biotechnology, vol. 68, no. 1, pp. 98103, 2005.

[21] Z. G. Qian, Z. J. Zhao, Y. Xu, X. Qian, and J. J. Zhong, "Novel synthetic 2,6-dichloroisonicotinate derivatives as effective elicitors for inducing the biosynthesis of plant secondary metabolites," Applied Microbiology and Biotechnology, vol. 71, no. 2, pp. 164-167, 2006.

[22] L. Tůmová, J. Tůma, M. Doležal, and B. Danielová, "Pyrazinecarboxylic acid derivatives as effective abiotic elicitors of isoflavonoids production," Ceska a Slovenska Farmacie, vol. 59, no. 3, pp. 117-122, 2010.

[23] L. Tůmová, J. Tůma, K. Megušar, and M. Doležal, “Substituted pyrazinecarboxamides as abiotic elicitors of flavolignan production in Silybum marianum (L.) gaertn cultures in Vitro," Molecules, vol. 15, no. 1, pp. 331-340, 2010. 
[24] V. Klimešová, M. Svoboda, K. Waisser, J. Kaustová, V. Buchta, and K. Králová, "Synthesis of 2-benzylthiopyridine-4-carbothioamide derivatives and their antimycobacterial, antifungal and photosynthesis-inhibiting activity," European Journal of Medicinal Chemistry, vol. 34, no. 5, pp. 433-440, 1999.

[25] O. L. Gamborg, R. A. Miller, and K. Ojima, "Nutrient requirements of suspension cultures of soybean root cells," Experimental Cell Research, vol. 50, no. 1, pp. 151-158, 1968.

[26] M. Kašparová, T. Siatka, J. Spilková, and J. Dušek, "Explant culture of Trifolium pratense L," Ceska a Slovenska Farmacie, vol. 55, no. 1, pp. 44-47, 2006.

[27] Czech Pharmacopoeia 2009, Grada Publishing, Prague, Czech Republic, 1st edition, 2009.

[28] E. De Rijke, H. C. Joshi, H. R. Sanderse, F. Ariese, U. A. T. Brinkman, and C. Gooijer, "Natively fluorescent isoflavones exhibiting anomalous Stokes' shifts," Analytica Chimica Acta, vol. 468, no. 1, pp. 3-11, 2002. 

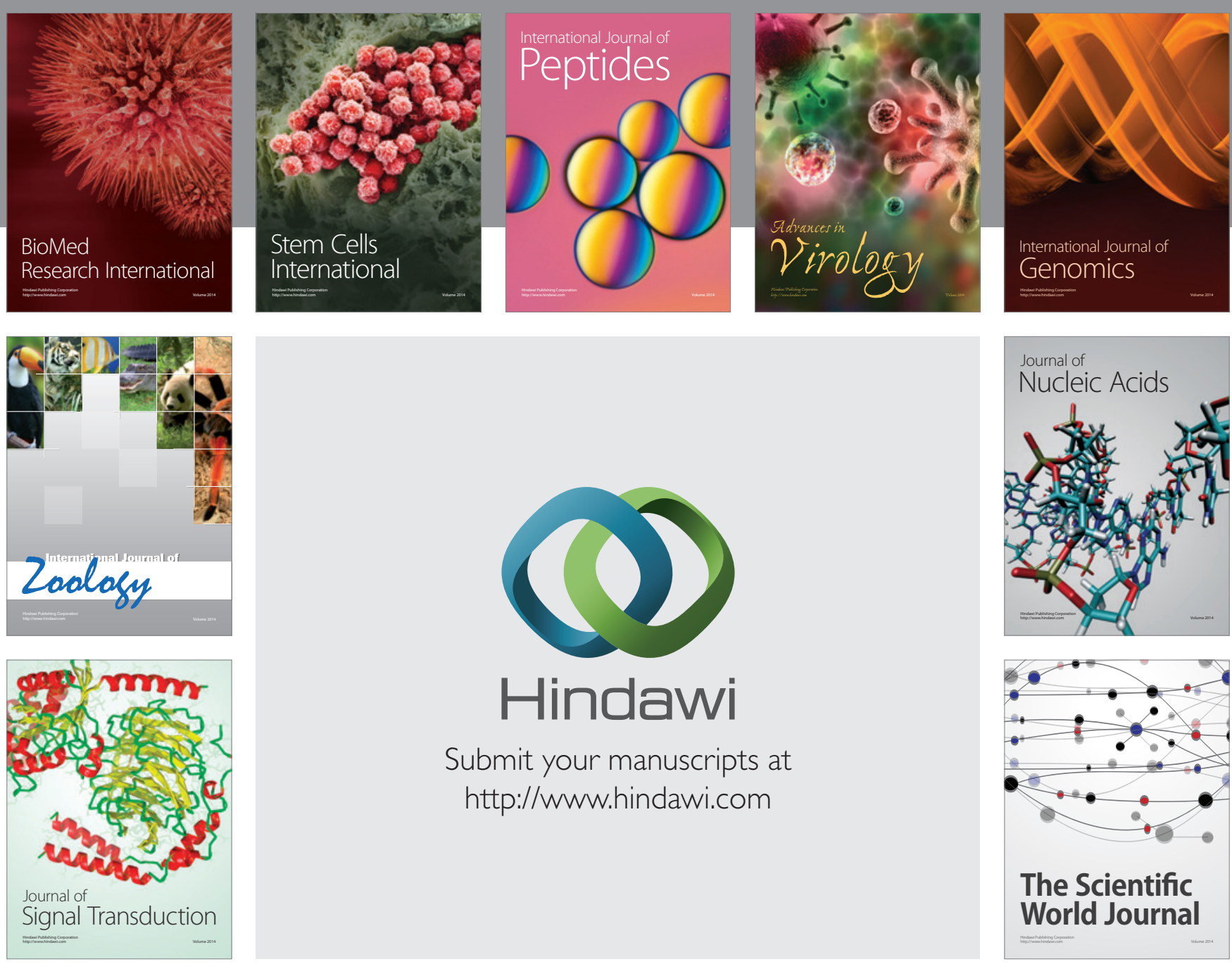

Submit your manuscripts at

http://www.hindawi.com
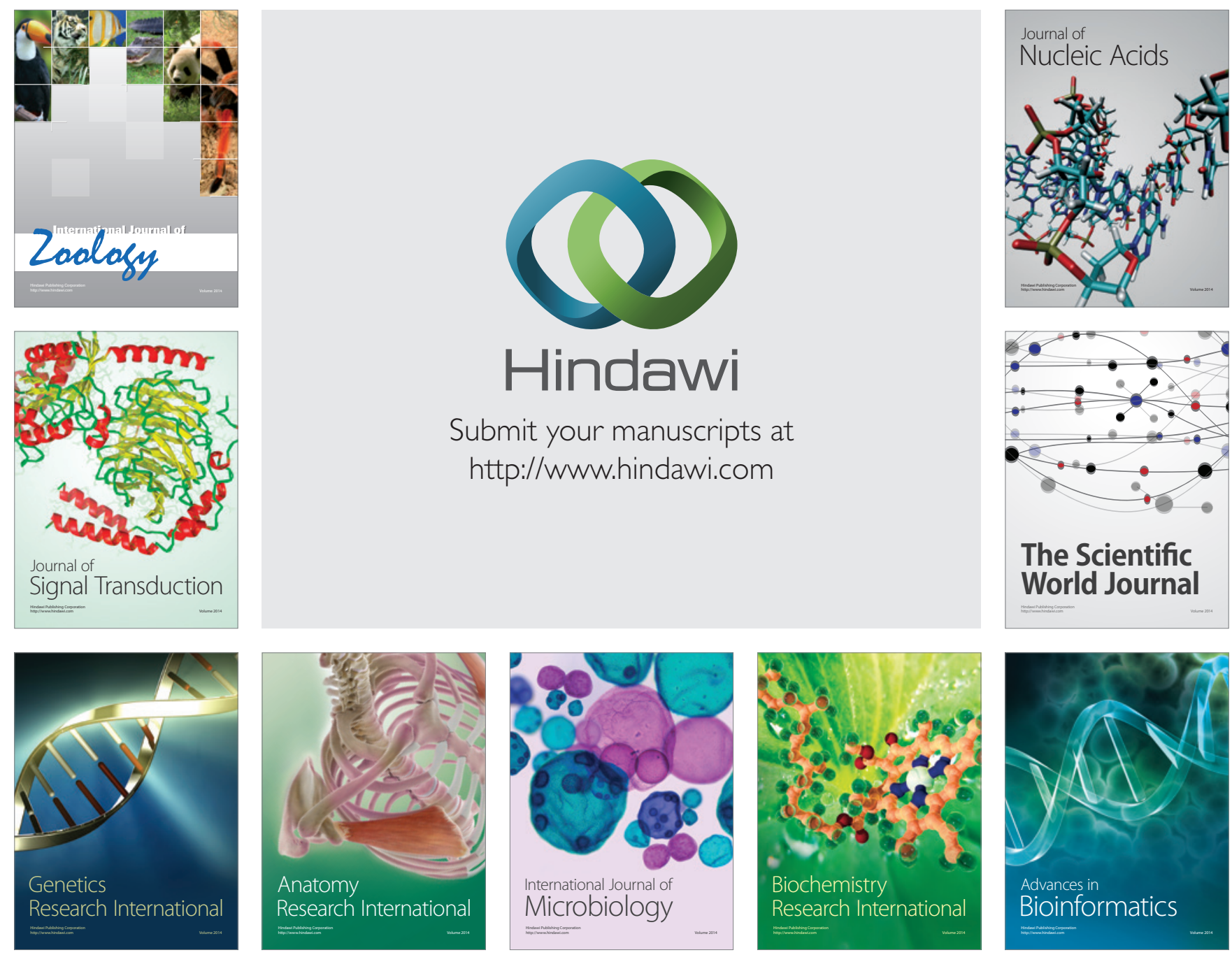

The Scientific World Journal
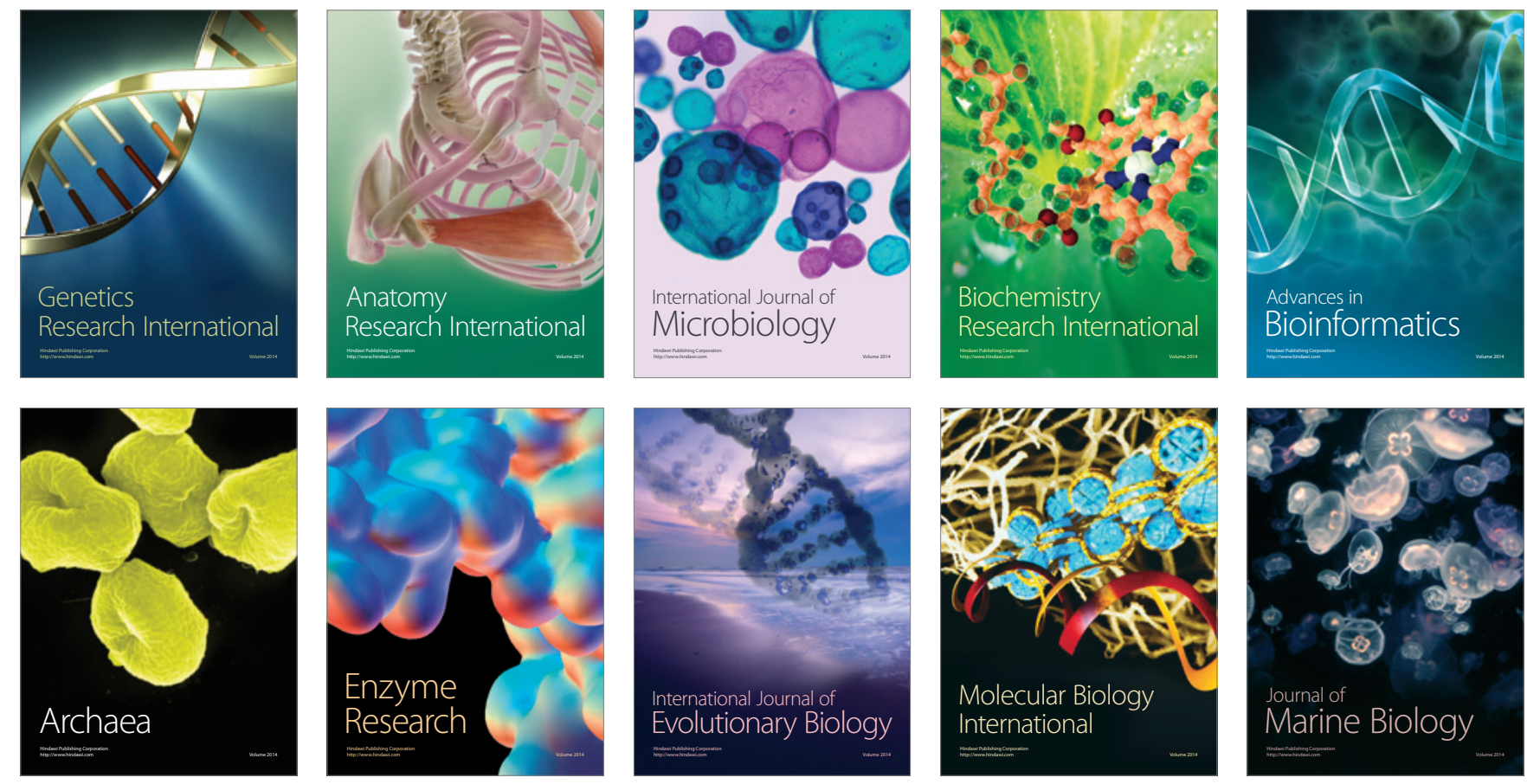